TITLE:

\title{
AN UNUSUALLY ROBUST CIONA FROM THE NORTHEASTERN COAST OF HONSYU ISLAND, JAPAN
}

$\operatorname{AUTHOR}(S)$ :

Hoshino, Zen'ichiro; Tokioka, Takasi

\section{CITATION:}

Hoshino, Zen'ichiro ...[et al]. AN UNUSUALLY ROBUST CIONA FROM THE NORTHEASTERN COAST OF HONSYU ISLAND, JAPAN. PUBLICATIONS OF THE SETO MARINE BIOLOGICAL LABORATORY 1967, 15(4): 275-290

ISSUE DATE:

$1967-12-20$

URL:

http://hdl.handle.net/2433/175476

RIGHT: 


\title{
AN UNUSUALLY ROBUST CIONA FROM THE NORTHEASTERN COAST OF HONSYU ISLAND, JAPAN ${ }^{\text {1) }}$
}

\author{
ZEN'ICHIRO HOSHINO \\ Department of Anatomy, Tôhoku University School of Medicine, Sendai, Japan \\ and \\ TAKASI TOKIOKA \\ Seto Marine Biological Laboratory
}

With Plate VII and 8 Text-figures

While the first author had been engaged for years in the studies of the comparative anatomy of the circulatory system and in the cytological researches of the heart of Ciona, he became aware of a very strange fact. Specimens of Ciona for his works were first collected from the rafts in the oyster farm of the Oyster Institute in Mone Inlet of Karakuwa-tyo, Miyagi Prefecture in the northeastern district of Honsyu Island. And he found two types of Ciona in his material from this locality. The one has the test which is very soft as usually known for cosmopolitan Ciona intestinalis (L.) and quite free from any foreign materials on the surface, and its mantle is more or less sprinkled with orange pigment spots, especially densely near the tip of siphons. The test of the other type is, however, much thicker and harder and sometimes even harbours other organisms on the surface; its mantle is scarcely pigmented. Moreover, it was found that the two types differ from each other markedly not only in the feature of the test but also in the formation of the endostylar appendage and in the arrangement of the epicardia and pharyngo-epicardiac openings as shown later. For the operation to remove the test and body wall on the right side to expose or take out the live heart, the soft Ciona is much more suitable than the robust Ciona, while in the robust Ciona the body contraction caused by external stimuli is much less than in the soft Ciona, because the contraction is much checked by the existence of the thick and hard test regardless the sensitivity and contractility of the mantle itself. Thus, the robust Ciona is much better for the pigment injection into the blood vessels under anesthetization by menthol. To secure these two types of Ciona for respective operations, Ciona in another locality, the fish rearing tanks of the Onagawa Fisheries Laboratory of 'Tohoku University, was examined, and it was found that there most of Ciona were of the robust type.

1) Contributions from the Seto Marine Biological Laboratory, No. 473.

Publ. Seto Mar. Biol. Lab., XV (4), 275-290, $1967 . \quad$ (Article 15) 
Now, it is the matter of essential necessity to know whether the soft Ciona and robust one are really only variants of a single species or they are separated distinctly from each other before the comparative anatomy of the circulatory system of Ciona is discussed, because the arrangement of the epicardia is defined by the arrangement of mesenteries and the relations between the mesenteries and the heart and alimentary canal are very significant for the detailed structure of the circulatory system. Thus he asked for help of the second author for taxonomical studies of these two types of Ciona. The second author made regular observations of the taxonomical ascidiology and consulted with references as far as possible. After a long hesitation, both authors reached the conclusion to separate the robust Ciona as a new species distinct from the soft Ciona which is treated in this paper tentatively as Ciona intestinalis (Linnaeus).

\section{Ciona robusta $\mathrm{n}$. $\mathrm{sp}$.}

Apparently there is seen a great variety in the external feature of the body. Thus, prior to present the general description, it seems necessary to give the descriptions of respective individuals of several specimens which were selected out of the material to show the gradual variation of the body feature. The following five individuals were treated for this purpose.

Specimen A: $50 \mathrm{~mm}$ long (Text-fig. $1 \mathrm{~A}$ ). The body is elongate, attached to the substratum by the posterior end; siphons are short, situated at the anterior end of the body, the atrial siphon is a little shorter than the branchial. The test is cartilaginous, solid and up to $1 \mathrm{~mm}$ in thickness in most parts except the posterior attachment portion where the test is much thicker. It is transparent near the tip of siphons, but translucent and yellowish in other parts and furnished with a number of tubercular prominences all over the surface. Some of these prominences are roughly arranged in longitudinal rows. Some prominences are very elongate antero-posteriorly; especially the branchial siphon is surrounded with seven longitudinal ridges. Most prominences are coloured rather brownish. A few small reddish brown colonies of Botryllus schlosseri are found attached to the test surface.

The released mantle body is $44 \mathrm{~mm}$ long, including $8 \mathrm{~mm}$ long siphons. A tuft of vascular vessels at the ventro-posterior corner of the body. Six longitudinal body muscle bands on each side of the body, all separated. On the right side (Text-fig. $3 \mathrm{~A}), \mathrm{V}$ and VI are united with each other at the posterior end, while on the left side III and IV approach each other in the posterior half. A pair of longitudinal muscle fascicules along the ventral median line, with the endostyle between them. Each body muscle band is roughly divided into two muscle strands, respectively consisting of a few to several muscle fascicules. The posterior part of the endostyle forms a very prominent endostylar appendage projected out from the branchial sac on the right side (Text-fig. $3 \mathrm{~A}^{\prime}$, Ed.ap.). The anus is situated a little anterior to the middle of the branchial sac and the margin is cut into about 10 lobules. The vas deferens 

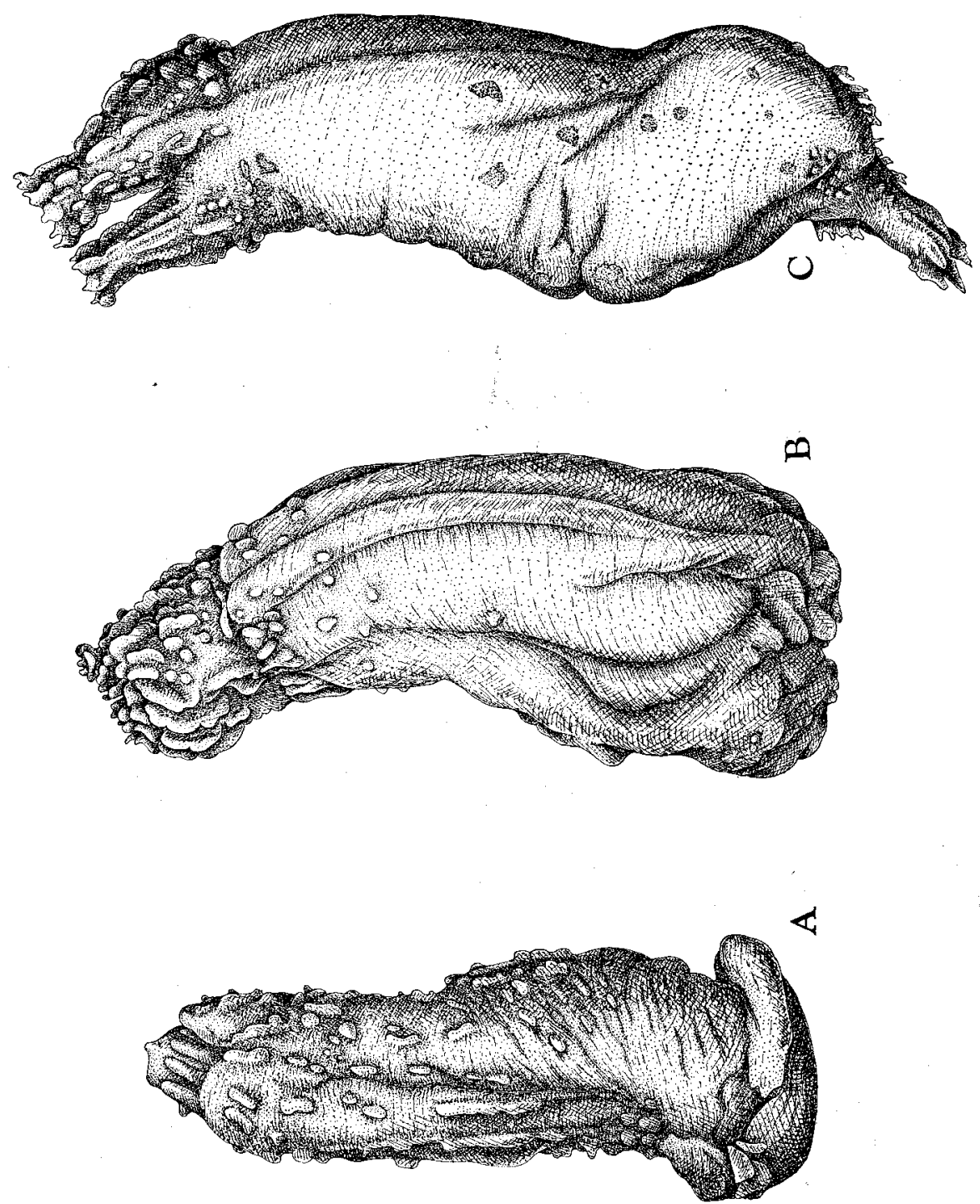

Fig. 1. Ciona robusta n. sp. Specimens with the hard cartilaginous test. A $\cdots$ Left side of Sp.

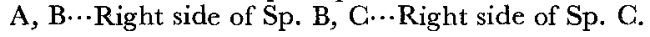

opens to the atrium very near the anterior end of the branchial sac through minute apertures respectively open at the distal end of 32 orange red papillae which are divided into the left and right tufts. The ovary opens near the right of these tufts (Text-fig. $5 \mathrm{~A}$ ). Eleven endocarps on the inner surface of the stomodaeum and 6 small ones on the inner surface of the atrial siphon. The biggest endocarp on the branchial siphon is $3 \mathrm{~mm}$ long. Twenty-four tentacles including large, intermediate and small ones, besides about 10 very minute ones. Ciliated groove is split into 


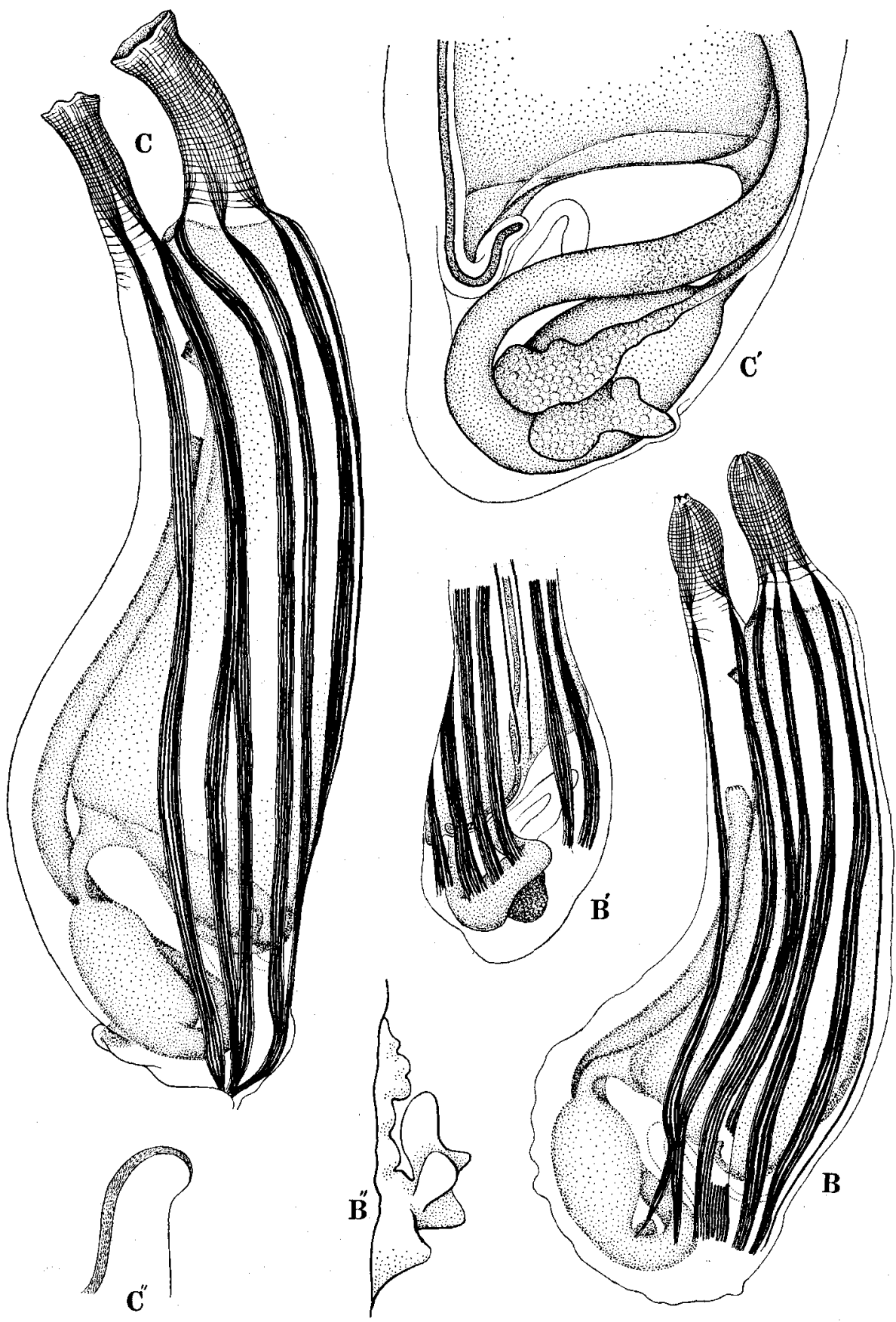

Fig. 2. Ciona robusta n. sp. B...Right side of mantle body of Sp. B; B'‥Posterior ventral side of mantle body of Sp. B; B"...Large endocarp from branchial siphon of Sp. B; C... Right side of mantle body of Sp. C; C ${ }^{\prime}$.... Left side of visceral region of Sp. $\mathrm{C} ; \mathrm{C}^{\prime \prime}$...Papilla at ințersection between inner longitudinal and transverse vessels, Sp. C. 
two pieces (Text-fig. $4 \mathrm{~A}$ ). Seventeen longitudinal vessels at the middle on the inner surface of the right half of the branchial sac and about 70 transverse vessels on the same side of the sac; 5-8 stigmata in a mesh. Pharyngo-epicardiac openings are situated near the base of the endostylar appendage far apart from the oesophageal opening (Text-fig. $3 \mathrm{~A}^{\prime}$ ).

Specimen B: $68 \mathrm{~mm}$ long individual (Text-fig. $1 \mathrm{~B}$ ), attached to the substratum by the left side near the posterior end of the body. The body appearance resembles closely that of the specimen A. Siphons at the anterior end of the body are both short. The tubercular prominences are fewer than in Sp. A. Prominences are limited in the anterior one-third of the body, some longitudinal ridges are roughly confined to the right side of the same portion. The feature of protuberances is just the same as in Sp. A. Other parts of the body are marked with a few longitudinal grooves. The test is soft cartilaginous and up to $2 \mathrm{~mm}$ in thickness.

The mantle body is $58 \mathrm{~mm}$ long including $12 \mathrm{~mm}$ long siphons (Text-fig. $2 \mathrm{~B}$ ). On the right side, the longitudinal body muscle bands I and II touch each other near the posterior end, III and IV are united with each other in the posterior half of the body, while V and VI are quite separated. On the left side, III and IV are separated from each other along the whole length. These longitudinal muscle bands are divided each into 2-3 strands ( 1 and 4 strands are presented respectively in one band), each consisting generally of 3 to 5 fascicules. A pair of longitudinal muscle fascicules on the ventral median line are distinct (Text-fig. $2 \mathbf{B}^{\prime}$ ). The endostyle, the anus and the male genital opening are structured and situated as in Sp. A. The anal margin is fringed with 14 lobules; openings of the vas deferens are 16 in all and divided into three groups (Text-fig. 5 B). A number of endocarps on the inner surface of siphons, the larger ones attain $2.5 \mathrm{~mm}$ in length (Text-fig. $2 \mathrm{~B}^{\prime \prime}$ ). Thirty-four tentacles including large, intermediate and small ones. Ciliated groove (Text-fig. $4 \mathrm{~B}$ ) opens to the left side (on the figure, to the right in the natural situation) and is cut at the base of the lower arm. Twenty-two inner longitudinal vessels at the middle on the right side of the branchial sac and 95 transverse vessels on the same side of the sac, 3-6 stigmata in a mesh. The first thick transverse vessel is found fairly posterior to the level of the genital apertures. About 8 thinner transverse vessels between each pair of thicker ones in the anterior half of the body; parastigmatic vessels present. Pharyngo-epicardiac openings are situated as in Sp. A, but they are much larger; especially the right opening is unusually large, attaining $2 \mathrm{~mm}$ in length (Text-fig. $3 \mathrm{~B}$ ).

Specimen C: $97 \mathrm{~mm}$ long, excluding $22 \mathrm{~mm}$ long attachment process situated at the posterior end of the body (Text-fig. $1 \mathrm{C}$ ). The body is attached to the substratum by the left side of the posterior end of the body including the attachment process. There are a number of papillae on the free surface of this attachment area. Siphons are short, but very distinct. The branchial aperture is surrounded by 8 and the atrial by 6 distinct lobes. Tubercular prominences like those in Sp. A and B, though they are 

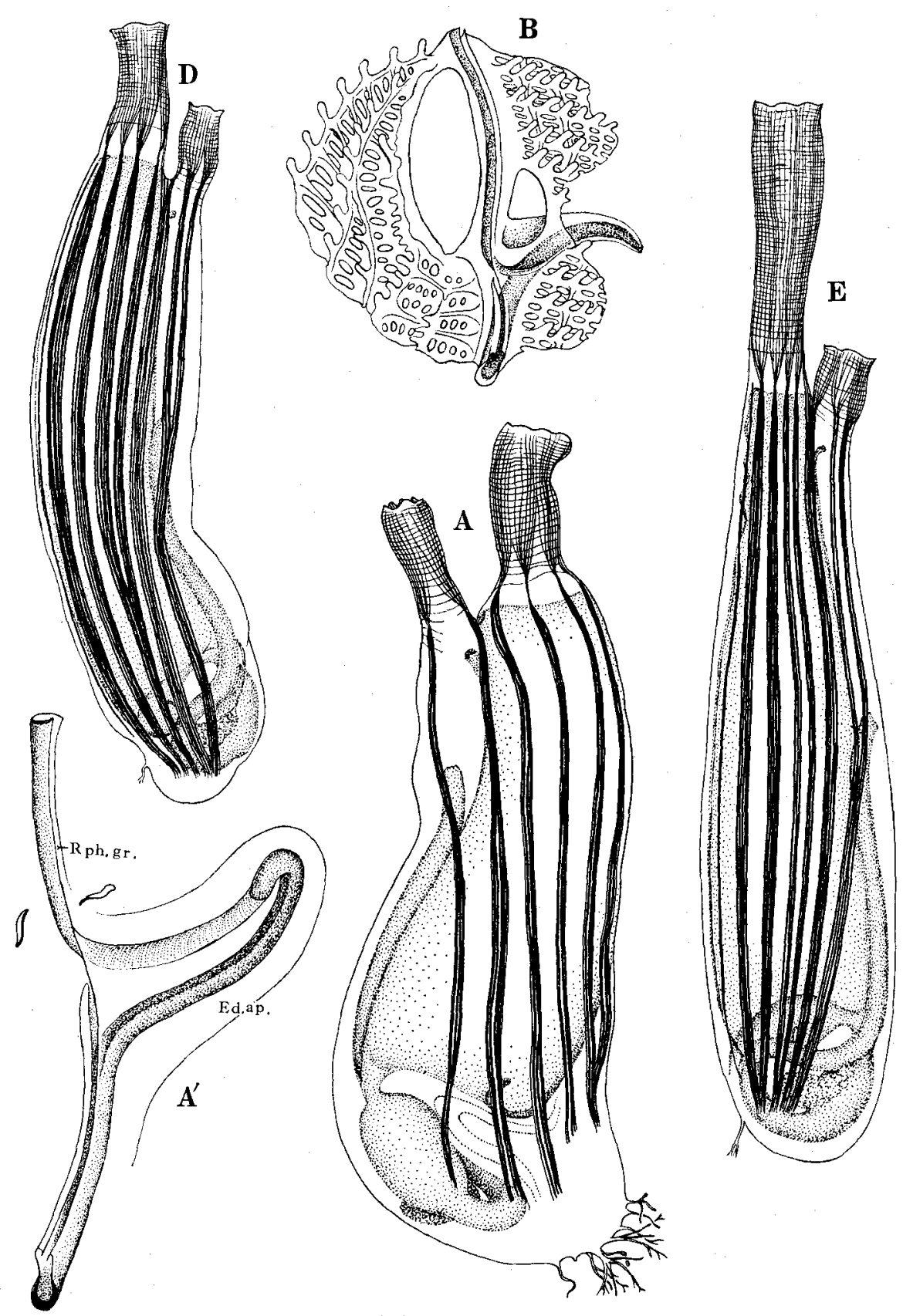

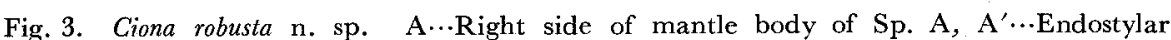
appendage of $\mathrm{Sp}$. A, left side; B...Pharyngo-epicardiac openings of $\mathrm{Sp}$. B, above-dorsal and below-ventral; D...Left side of mantle body of Sp. D; E..Left side of mantle hody of Sp. E. Ed. ip....endostylar appendage, Rph. gr...retropharyngeal groove. 
much fewer than in those specimens and confined to the anterior one-fourth of the body. Some of them are arranged in 4 ridges on the dorsal and in 8 on the ventral side. Other parts of the body are usually smooth throughout, except for a few grooves which are probably produced by contraction of the body at fixation. The test is cartilaginous, hard enough and generally about $2 \mathrm{~mm}$ in thickness, though up to $5 \mathrm{~mm}$ near the posterior end of the body. Some reddish brown colonies of Botrylloides and byssus remnants of some mytilid bivalves are found on some parts of the test surface.

The mantle body is $64 \mathrm{~mm}$ long, excluding $16 \mathrm{~mm}$ long branchial and $14 \mathrm{~mm}$ long atrial siphons. The mantle is extremely delicate and quite transparent; a strong vascular prominence at the postero-ventral corner of the body. Eight ocelli at the branchial and 6 at the atrial aperture. The general feature of the body longitudinal musculature is just the same as in Sp. A and B. Muscles I and II extend onto the atrial and III-VI onto the branchial siphon. Some muscle fascicules of II may extend onto the branchial siphon, too. All muscles are separated on both sides. The muscle II is partly split into 2 branches on its way in the posterior half on the right side. All muscle bands, except the pair of longitudinal muscle fascicules on the ventral median line, consist each of 3-4 (most frequently 4) strands and 7 to 15 fascicules. The anus is plainly margined in an extended state and open at the anterior one-third of the body. The male genital apertures (Text-fig. 5, C, C') open at the level of the middle of the range between the anus and the anterior end of the branchial sac. The alimentary organs posterior to the level of the oesophagus (Text-fig. $2 \mathrm{C}^{\prime}$ ) occupy the posterior one-fourth to one-third of the mantle body. A few elongate endocarps on the inner surface of siphons on some of the longitudinal planes includ-
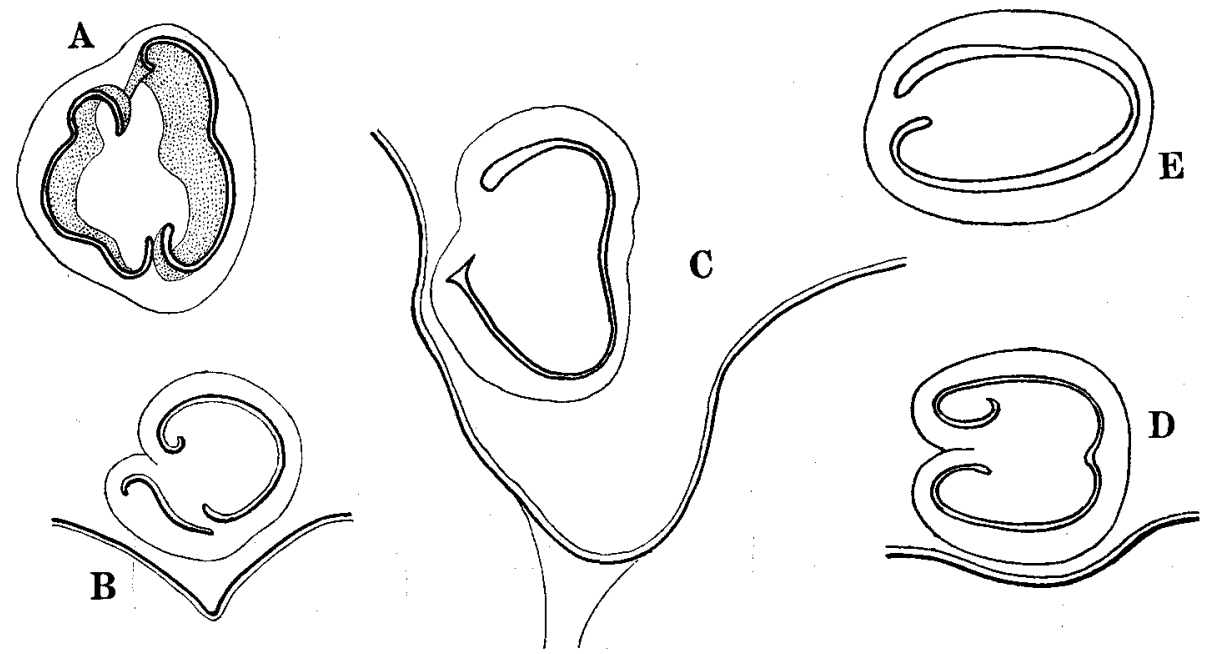

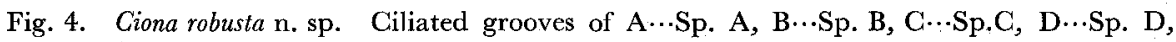
and E...Sp. E. 
ing respectively an ocellus. Only 5 large and 3 small tentacles are found; most probably such a small number of tentacles is due to some injury. The ciliated groove opens to the left side (on the figure, Text-fig. $4 \mathrm{C}$ ) and is situated at the anterior end of the dorsal ganglion. Dorsal languets very distinct. Twenty-four inner longitudinal vessels at the middle on the right side of the branchial sac, and about 120 stigmata rows on the same side of the sac. Transverse vessels are arranged roughly in the order-thick thin thin thin thick-, parastigmatic vessels present. Eight to 10 stigmata in a mesh, no plications are formed. Papillae at the intersections between the longitudinal and transverse vessels are very simple, with a ciliated band along the ventral edge (Text-fig. $2 \mathrm{C}^{\prime \prime}$ ). Pharyngo-epicardiac openings as in Sp. A and $B$; they are small and the left opening is a little dorsal to the right one.

Specimen D: Very elongate $70 \mathrm{~mm}$ long individual (Pl. VII, D) attached to the substratum by the left side at the posterior end of the body. The test is gelatinous, very thin, and quite transparent; it is as soft as the test of typical Ciona intestinalis. Only the anterior portion of the body including siphons is a little rigid and furnished with a number of irregularly-shaped tubercular prominences. Several thin longitudinal ridges are found in the anterior half of the body. Both siphons distinct and situated at the anterior end of the body; the branchial is much longer than the atrial.

Longitudinal body muscle bands (Text-fig. $3 \mathrm{D}$ ) are as in Sp. A-C. The muscles III and IV are united with each other in the posterior one-third on both sides. The muscle $I$ is split in the anterior half on the left and in the anterior two-thirds on the right side into 2 branches; other muscles are all separated. A pair of the thin longitudinal muscle strands along the ventral median line consist each of 1-2 fascicules. Each longitudinal body muscle band except the ventral much thinner pair consists of 5-8 strands. The anus is open at the level of the middle of the branchial sac. The genital apertures situated near the anterior end of the sac. About 40 tentacles including larger and smaller ones. The ciliated groove (Text-fig. $4 \mathrm{D}$ ) opens to the
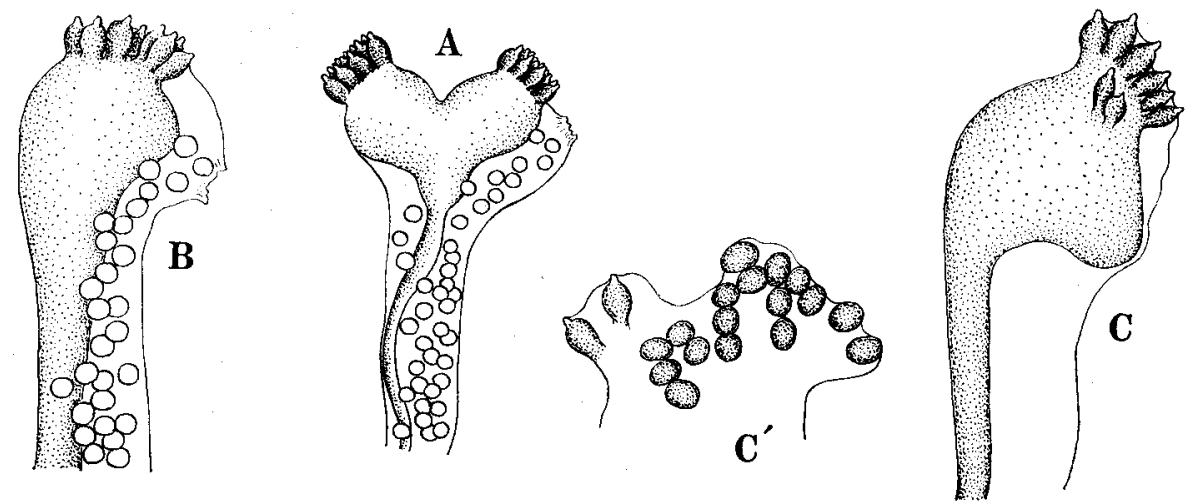

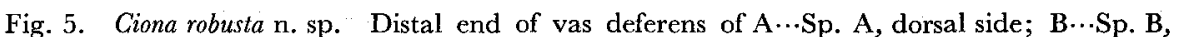
left side; G...Sp. C, left side; and $\mathrm{C}^{\prime}$-...Sp. $\mathrm{C}$, dorsal side. 
left side (on the figure). Twenty-seven inner longitudinal vessels at the middle on the right side of the branchial sac, and about 100 stigmatal rows on the same side of the sac; parastigmatic vessels present. Pharyngo-epicardiac openings as in Sp. A-C, the left opening is a little dorsal to the right.

Specimen E: $80 \mathrm{~mm}$ long individual (Pl. VII, E). The outline of the body and the structure of the test are as in Sp. D. The test is softest throughout the treated five specimens; the whole surface is nearly smooth except for a few small prominences on siphons and a considerable number of papillae near the postero-ventral corner of the body.

The longitudinal body muscle bands (Text-fig. $3 \mathrm{E}$ ) resemble closely those of Sp. D. The muscles I and II, III and IV, and V and VI are united respectively at the posterior end. On the right side, III and IV are united along the whole length; thus superficially there are seen only five muscle bands. Each muscle band consists of 6-9 strands except for III and IV which consist each of 3 strands on the left side. The relative situations of the anus and the genital apertures as in Sp. D. Sixty-two tentacles including a small number of smaller ones. The ciliated groove (Text-fig. $4 \mathrm{E}$ ) as in Sp. D. Twenty-eight inner longitudinal vessels at the middle on the left side of the branchial sac, and 137 stigmata rows on the same side of the sac; parastigmatic vessels present. Pharyngo-epicardiac openings as in Sp. A-D, the right opening is fairly dorsal to the left one.

Throughout the three specimens with the hard cartilaginous test and the two with the soft gelatinous test, the following may be accepted as the general description for the present species.

The body is elongate, reaching to $100 \mathrm{~mm}$ long at the maximum, and attached to the substratum by the posterior end or more frequently by the left side near the posterior end of the body. The test is very variable in consistency and thickness; some individuals bear the test as soft as in typical Ciona intestinalis, while there are a lot of individuals with the test which is cartilaginous and so robust that such individuals in a preserved state in formalin can be held upright by fingers (Pl. VII, top photograph). The rigidity of the test is quite continuous from hard to soft. At fixation, the deformation of the body occurs much more remarkably in the individuals with the soft test than in those with the hard test. On the contrary, at anaesthetization, the relaxation of the body will be attained much more extensively in the individuals with the soft test than in those with the hard test; this is very prominent in the morphology in the anterior portion of the body. Both siphons are situated at the anterior end of the body. They are nearly of equal length in individuals with the hard test, but in those with the soft test the branchial is evidently longer than the atrial. On some specimens, the lobation around the siphonal apertures is rather distinct; then 8 lobules on the branchial and 6 on the atrial siphon are discernible. The test may attain to 1-2 $\mathrm{mm}$ in thickness in the anterior part of the body and $5 \mathrm{~mm}$ at the posterior 
attachment portion in individuals with the hard test. In these specimens, the test surface, at least in the anterior portion, is provided with different numbers of tubercular prominences. Some prominences are papilla-shaped, but some others may be elongate and assume a kind of short ridge and be arranged antero-posteriorly to form some longitudinal rows; this is met with frequently in the anterior portion of the body including siphons. Such protuberances are found also in individuals with the soft test, most abundantly in the anterior part of the body. At the least, they are represented by a number of papillae in the proximal portion of the body. The soft test is very thin, colourless, and transparent. But the test transparency decreases with the thickness and hardness, and the test surface becomes yellowish or somewhat brownish. This colouration is most pronounced on the tubercular prominences. The surface of the robust test may be covered partly by colonies of some compound ascidians or some mytilid bivalves and thus the test becomes quite opaque.

The mantle is very delicate as in typical Ciona intestinalis, the internal structure of the body can be seen through it. It is faintly greenish, but devoid of any orange pigmentation, except ocelli on the siphonal margin, 8 on the branchial and 6 on the atrial siphon. Usually a vascular vessel is issued from the postero-ventral corner of the body, though there may be found a number of vessels at that position in some individuals.

There are 6 longitudinal body muscle bands on each side of the body. Some of pairs of adjoining bands may be united near or at the posterior end, or some bands may be divided into 2 branches anteriorly or partly at some part of their course. Most frequent are the fusion of muscles III and IV in the posterior half (exceptionally along the whole length) of the body and the split of $I$ in the anterior half of the body. The muscle bands are divided each into 2 (in smaller specimens) to 8 (in larger specimens) strands, each of them then consisting of a few to several muscle fascicules. Because of complicated anastomoses, the exact number of fascicules in respective muscle bands can hardly be given. The transverse musculature inside the longitudinal musculature consists of very many thinner muscle strands. The siphonal musculature as in Ciona intestinalis. A pair of longitudinal muscle strands are found along the ventral median line, with the endostyle between; the strand consists of a single or 2 muscle fascicules.

The stomach is situated posterior to the rear end of the branchial sac, which is extended a little more posteriorly on the right side than on the left side (Text-fig. 2, $\left.\mathbf{B}^{\prime}\right)$. The anus opens near the middle of the branchial sac in the specimens in which the anterior portion of the body is well extended, while it is situated much more anteriorly in those in which the anterior portion of the body is not extended so well. It is plainly margined in a fully extended condition, but in a more or less contracted state the margin is cut into a number of lobules. The genital apertures are situated near the anterior end of the branchial sac. The distal end of the vas deferens is divided into 2-3 sections, each crowned with a tuft of orange red ellipsoidal papillae. 
Many, up to 32, male genital apertures are opening one on each papilla at the tip of the mammillary prominence at the distal end of the papilla. A single female genital aperture opens near the distal end of the vas deferens (Text-fig. 5, A, B). There are a few to several endocarps on the inner surface of siphons on lines passing through respective ocellus; larger ones may reach to $2-3 \mathrm{~mm}$ in length. The number of tentacles is quite irregular, it is not regularly related with the body size. In some individuals, tentacles are as many as 60, but in some others they are fewer than 30 . Partly the regular arrangement of tentacles, - large small median small large- or - large small large-, may be seen in some individuals. A small number of minute tentacles may be present. The ciliated groove is situated at the anterior end of the dorsal ganglion and generally opened to the left side (on the figure). Sometimes it may be split into 2 pieces. Numbers of inner longitudinal and transverse vessels vary roughly with the body size:

$\begin{array}{lcc}\text { Body length } & \begin{array}{c}\text { Inner longitudinal } \\ \text { vessels }\end{array} & \text { Transverse vessels } \\ 50 \mathrm{~mm} & 17 & 70 \\ 68 & 22 & 95 \\ 70 & 27 & \text { about } 100 \\ 80 & 28 & 137 \\ 97 & 24 & 120\end{array}$

As to transverse vessels, the arrangement of - thick thin thin thin thick-is met with most frequently. Parastigmatic vessels present. Papillae at the intersections between the longitudinal and transverse vessels are simple and furnished with a ciliary band along the ventral edge. No plications are formed on the branchial sac. Five (in smaller meshes) to 10 (in larger meshes) stigmata in a mesh. Dorsal languets very distinct. The ovary is situated in the first intestinal loop on the left side of the stomach.

The posterior end of the endostyle is curved to the right dorsal side and protruded out together with the ventral end of the retropharyngeal groove to form a prominent endostylar appendage in the left epicardium. Pharyngo-epicardiac openings are situated near the base of this appendage (Text-fig. 6, ROB; Text-fig. 8, ROB 3--3). The actual situation of respective openings and their size are somewhat variable. Both openings are usually situated outside the retropharyngeal groove, although the left one may occur sometimes within the groove. The heart is held on the inter-epicardiac septum between the right and left epicardia, which consists of two lining cell layers, respectively of the right and the left epicardium. In other words, the outside of the heart is covered on the right side with the lining cell layer of the right epicardium and on the left side with the lining cell layer of the left epicardium. And the mesenteries supporting the heart, namely the septal wall between the right and left epicardia, is composed of the linings of the right and left epicardia, closely adhering to each other (Text-fig. 8, ROB, 2-2 and 3-3). 


\section{Discussion}

MillaR's book (1953) may be accepted as the latest comprehensive descriptions of Ciona intestinalis. Millar (1953), VAN Name (1945), and Berrill (1950) agree with one another to consider $C$. intestinalis as the only valid species in the genus Ciona, though a few varieties or forms are admitted. The above-described Ciona robusta conforms well to $C$. intestinalis in the internal structure, including the formation of the endostylar appendage (Millar, 1953, Fig. 35), the situation of pharyngo-epicardiac openings (Millar, 1953, Fig. 29), and the envelope of the heart (BerRill, 1950, Fig. 40 D; Millar, 1953, Fig. 52). However, so far as the authors are concerned, no reference has been made to the existence of the hard test which is so thick and robust that the preserved specimens can be held upright.

On the other hand, the soft Ciona noticed by the first author has always very soft and flabby test of gelatinous consistency. The test is colourless and transparent, and the surface is smooth, never furnished with any projections, and of course quite free from any foreign materials. The mantle is often pigmented orange, most frequently and densely at the anterior end of the body, especially on siphons. Owing to such a structure, the animal is very sensitive to external mechanical stimuli and contracts
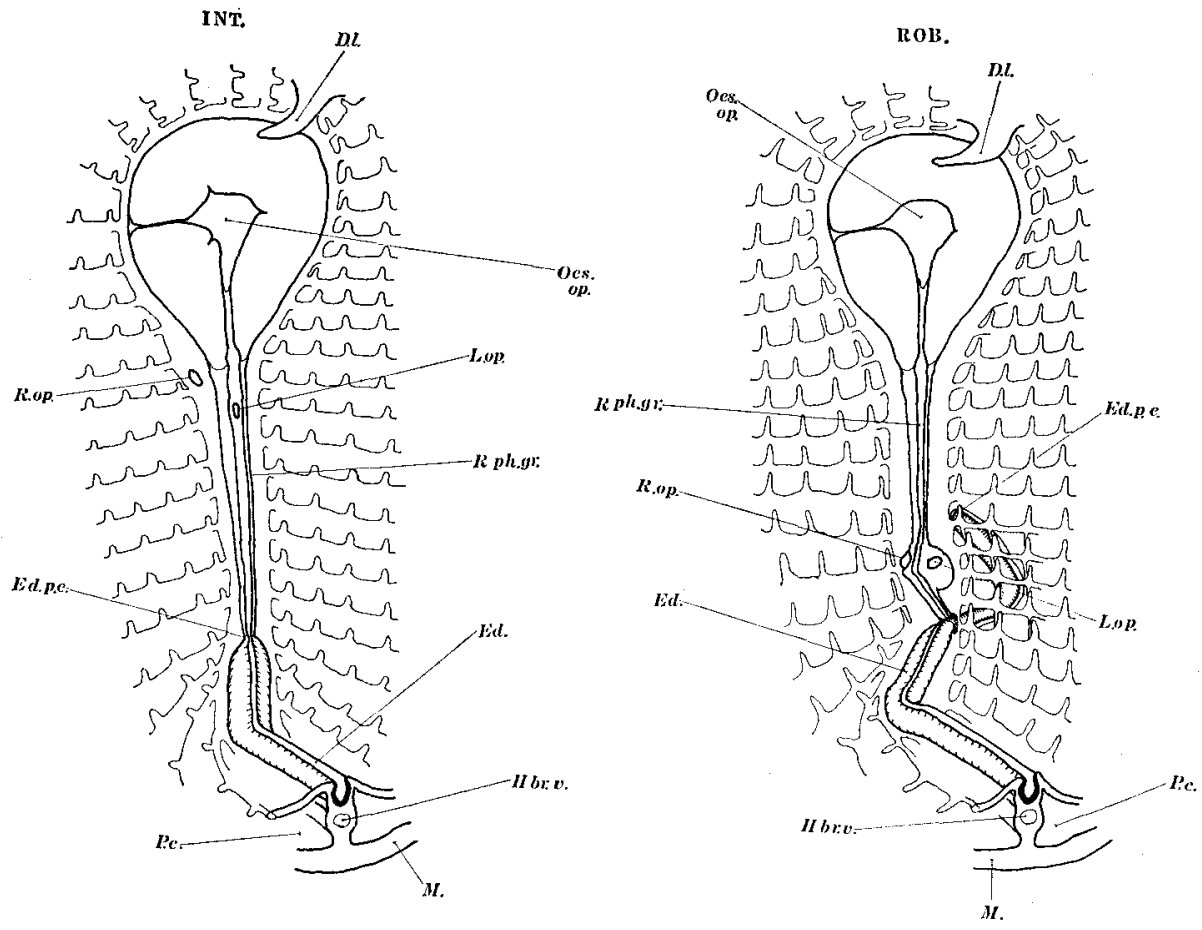

Fig. 6. Bottom of branchial sac of Ciona. INT...Ciona intestinalis (L.), ROB...Ciona robusta n. sp. For captions see Fig. 7. 
easily and strongly. These features resemble closely those of C. intestinalis.

It is very noteworthy, however, that some of the internal structures differ distinctly between the soft Ciona and C. robusta. In soft Ciona, the posterior end of the endostyle continues nearly straight to the retropharyngeal groove without protruding out to form the prominent endostylar appendage, and the pharyngo-epicardiac openings are situated far apart from the posterior end of the endostyle and near the oesophageal opening (Text-fig. 6 INT, ref. ROB. of the same figure; Text-fig. 8, 1-1 INT.). The right opening is generally situated outside the retropharyngeal groove, but the left opening is situated a little ventral to the right and frequently within the groove. The other significant feature is that the heart is held by both the posterior wall of the right peribranchial cavity and the lining of the epicardium (Text-fig. 8,

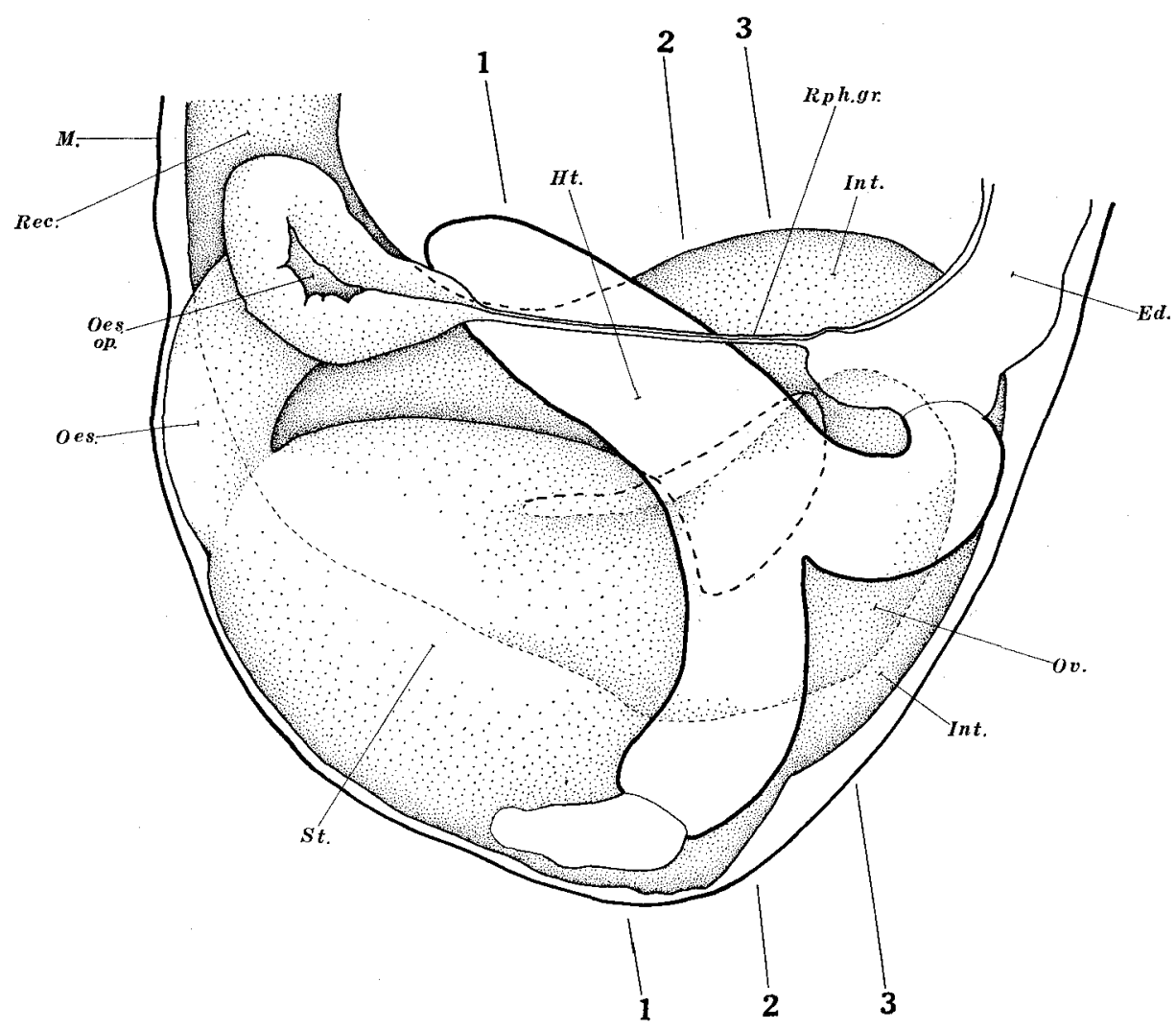

Fig. 7. Schema of the visceral region of Ciona, right side. Sections through 1-1, 2-2, and

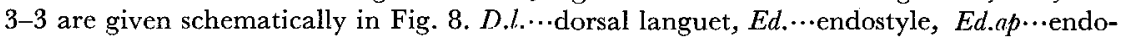

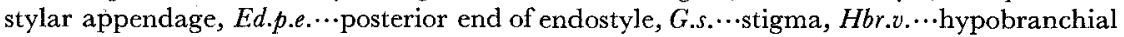

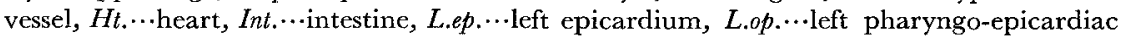

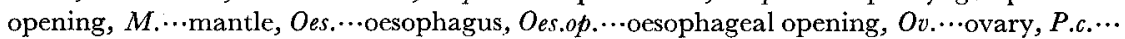

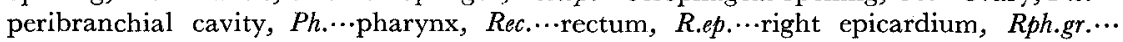
retropharyngeal groove, $R . o p$...right pharyngo-epicardiac opening, St...stomach. 

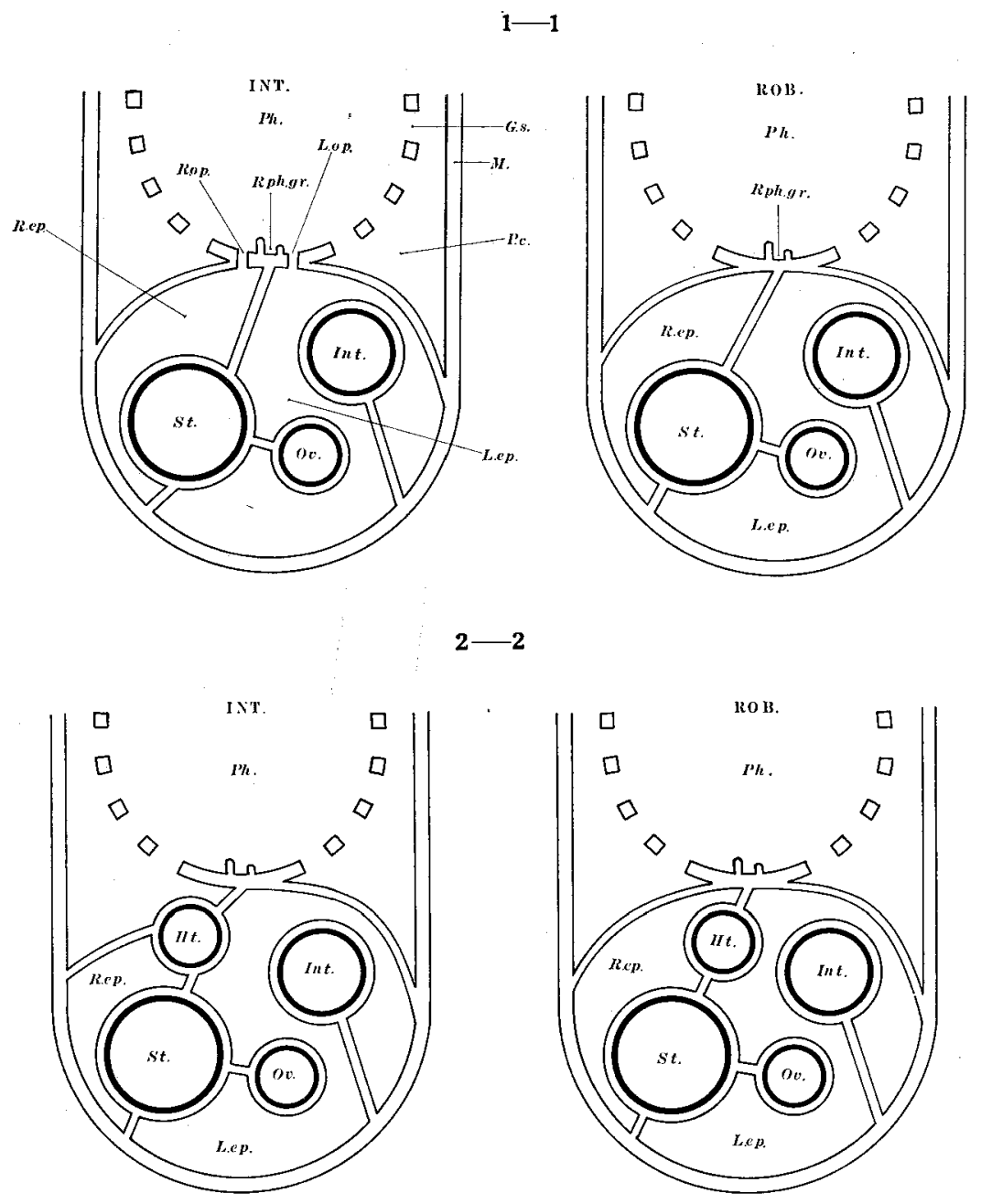

$3-3$
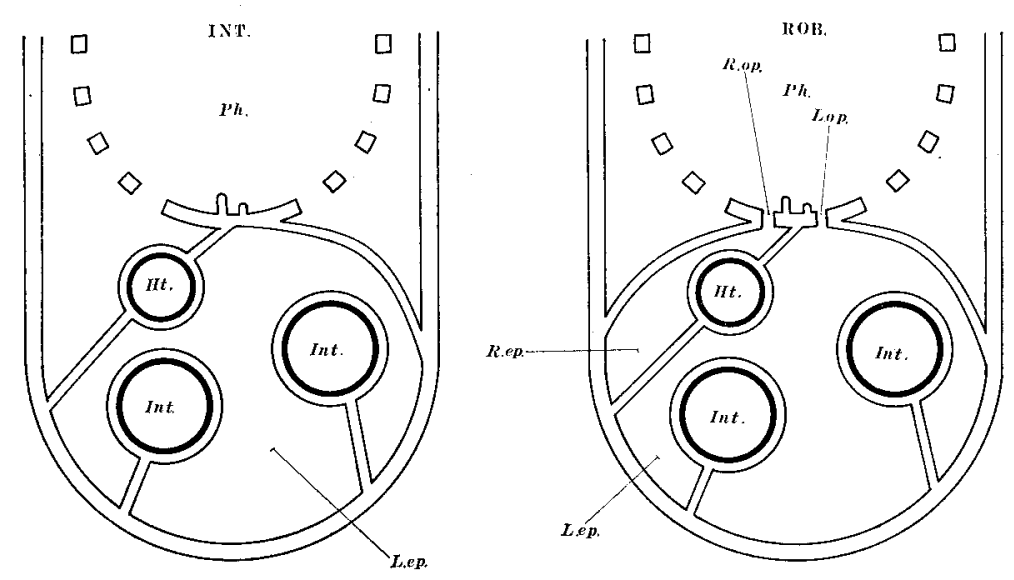
INT. 2-2, 3-3). In Section 2--2 (Text-fig. 8), the heart is supported anteriorly by the membrane consisting of the posterior wall of the right peribranchial cavity and the lining of the left epicardium and posteriorly by two membranes, the right one is composed of the posterior wall of the right peribranchial cavity and the lining of the right epicardium and the left one is the mesentery and, at the same time, the interepicardiac septum between the right and left epicardia. The outer-most layer of the heart envelope consists of the posterior wall of the right peribranchial cavity, the lining of the right epicardium, and the lining of the left epicardium. In Section $3-3$, the outer-most layer of the heart envelope is the posterior wall of the right peribranchial cavity on the right side and the lining of the left epicardium on the left side. And the heart is supported by the membrane made of the posterior wall of the right peribranchial cavity and the lining of the left epicardium. Such features show that the right epicardium is much narrower in the soft Ciona than in C. robusta. In $C$. robusta the right epicardium extends over the whole right side of the visceral portion of the posterior body, while in the soft Ciona the right epicardium is limited to the space extending from the right side of the oesophagus on the dorsal side to the level of the dorsal branch of the $\mathrm{V}$-shaped heart on the ventral side.

The above-mentioned differences in the structure of the endostylar appendage, the situation of pharyngo-epicardiac openings, and the relative arrangement of the heart and the right epicardium were confirmed by the first author in 20 individuals of the soft Ciona and 30 individuals of C. robusta; no intermediate individuals have been found. Although the test feature varies fairly in C. robusta, it is rather easy to distinguish the soft Ciona and C. robusta from each other in the natural environment. Individuals of $C$. robusta grown up in the fish rearing tanks of the Onagawa Fisheries Laboratory of Tôhoku University are devoid of foreign materials on the body surface and thus some of them look superficially like the soft Ciona, as the test is rather translucent. But really, the internal structure is just the same as in individuals with the hard thick test. Generally saying, $C$. robusta seems physiologically stronger than the soft Ciona, as the former can be kept alive under the indoor laboratory conditions more easily and much longer than the latter.

The question is which of $C$. rabusta and the soft Ciona does represent Ciona intestinalis. From the structure of the test, the soft Ciona is very likely to be Ciona intestinalis. However, the internal structures referred to above in the soft Ciona seem to differ a little from the descriptions given by previous authors for $C$. intestinalis. And to-day, it is impossible to know if LinNaEus' type of Ciona intestinalis was constructed as the soft Ciona or it was an individual of C. robusta which was provided with the soft test. It is impossible for the present authors, either, to examine the internal structures of a considerable number of individuals of Ciona intestinalis from different locali-

Fig. 8. Schematic representations of antero-posterior sections of the visceral region of Ciona at 1-1, 2-2, and 3-3 shown in Fig. 7. INT.... Ciona intestinalis (L.), ROB...Ciona robusta n.sp. To make clear the schema, the heart is not shown in 1-1, the outline of the heart is much simplified in 2-2, and the ovary is not given in 3-3. For captions see Fig. 7. 
ties in European and American waters to learn whether or not the two types of Ciona have been treated confusedly by previous authors. At present, the resemblance of the test appearance is tentatively estimated most highly and the soft Ciona is identified provisionally as Ciona intestinalis. Then C. robusta must be treated as a new species separated distinctly from Ciona intestinalis. Far ago, Herdman (1886) described Ciona aspera basing on a single small specimen collected by the Challenger off Kobe. The test surface of this Ciona was covered by very irregular, short sharp-pointed projections, and this was especially remarkable near the posterior end of the body. The corrugations of the test in the anterior part of the body might be caused by contraction of the body, but the surface roughness in the posterior part of the body seemed quite natural. This feature of $C$. aspera reminds the present authors of Sp. $\mathrm{E}$ of $C$. robusta. But actually, it must be very difficult to-day to clear the details of the internal structure of the small contracted type of $C$. aspera. For this reason, it is avoided here to identify the robust Ciona as C. aspera Herduan. It is hoped earnestly that, being stimulated by the present paper, Ciona intestinalis will be re-examined from various morphological points.

The five described specimens, Sp. A-Sp. E, from Onagawa are deposited as syntype at the Seto Marine Biological Laboratory and other specimens from the same locality are kept as paratypes.

Acknowledgements: Before closing the present note, the first author wants to express here his hearty thanks to Dr. Ryôzi URA, former director of Department of Anatomy, Tóhoku University School of Medicine, for his kindness in giving the chance to start the present study, to Dr. Takeo ImaI, director of the Oyster Institute, and Dr. Kiyoshige Sekino, associate professor of the Onagawa Fisheries Laboratory of Tôhoku University, for their kind help in collecting specimens and also for their valuable advices.

\section{REFERENCES}

(For other references for Ciona intestinalis refer MiLlaR, 1953.)

Ärnbäck-Christie-Linde, A. et Brien, P. (1932): Remarques au sujet du post-abdomen des Cionidae. Annal, Soc. Roy. Zool. Belgique, Vol. 43, pp. 41-53, 7 text-figs.

Berrill, N. J. (1950): The Tunicata. Ray Society, pp. 129-134, text-figs. 40-41.

Herdman, W.A. (1886): Report on the Tunicata collected during the voyage of H.M.S. Challenger during the years 1873-1876. Part 2. Ascidiae Compositae, Appendix A. Challenger Report, Zool. Vol. 14, pp. 416-418, Pl. 49, figs. 11-13.

Millar, R. H. (1953): Ciona. L.M.B.C. Memoirs, 35, 123 pp., 19 pls.

Van Name, W.G. (1945): The North and South American ascidians. Bull. American Mus. Nat. Hist., Vol. 84, pp. 160-164, text-figs. 79-80.

\section{EXPLANATION OF PLATE VII}

Top photograph.... Other two specimens of Ciona robusta n.sp. held upright by fingers. (Ch. Araga photo.)

D, E. ….............. Ciona robusta n.sp., specimens with the soft gelatinous test. D $\cdots$ Right side of Sp. D, E $\cdots$ Right side of Sp. E. 
Publ. Seto Mar. Biol. Lab., XV (4), 1967.

PLATE VII
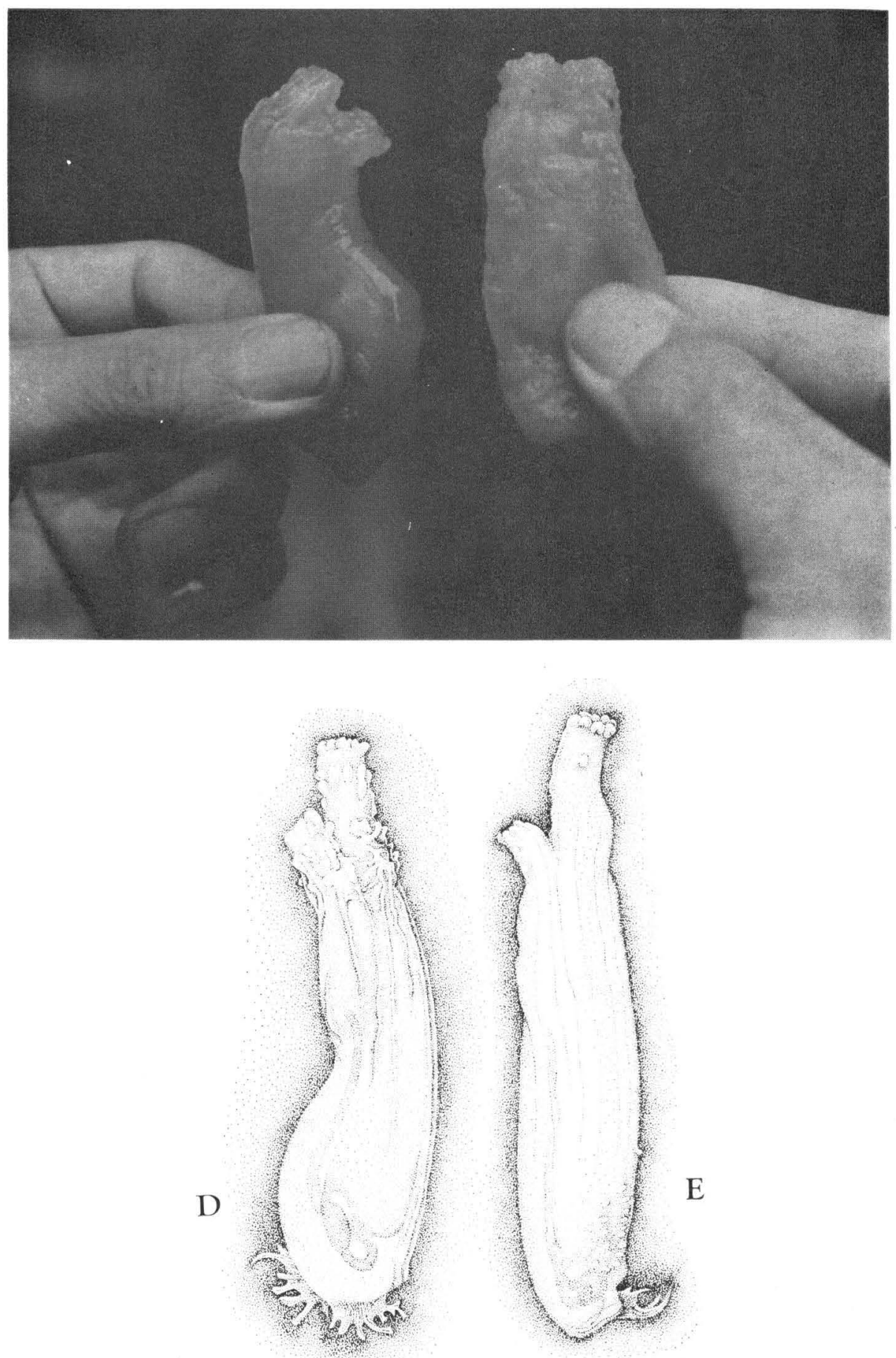

Z. Hoshino and T. Tokioka: Unusually Robust Ciona from Japan 